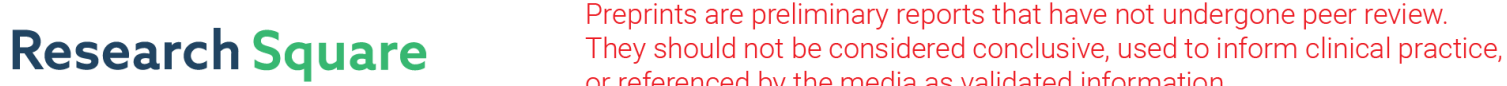 or referenced by the media as validated information. \\ Variations of the Precipitation Extremes over the Guangdong- Hong Kong-Macao Greater Bay Area in China
}

\section{Xianru Li}

Beijing Normal University

Zhigang Wei ( $\nabla$ wzg@bnu.edu.cn )

State Key Laboratory of Earth Surface Processes and Resource Ecology https://orcid.org/0000-0003-0938-8489

\section{Huan Wang}

Beijing Normal University

Li Ma

Beijing Normal University

\section{Shitong Guo}

Beijing Normal University

\section{Research Article}

Keywords: extreme precipitation, the Guangdong-Hong Kong-Macao Greater Bay Area, Interannual oscillation, Trend

Posted Date: September 3rd, 2021

DOI: https://doi.org/10.21203/rs.3.rs-553653/v1

License: (c) (i) This work is licensed under a Creative Commons Attribution 4.0 International License. Read Full License

Version of Record: A version of this preprint was published at Theoretical and Applied Climatology on October 29th, 2021. See the published version at https://doi.org/10.1007/s00704-021-03829-0. 


\section{Abstract}

By using the gridded $0.25^{\circ} \times 0.25^{\circ}$ observation dataset of CN05.1 provided by the China Meteorological Administration, this study investigates the variations of the nine precipitation extreme indices over the Guangdong-Hong Kong-Macao Greater Bay Area (GBA) in China in the period from 1961 to 2018. Based on trends and inter-annual variations, the nine kinds of extreme precipitation are classified into four categories: the category 1 is the very wet days (R95P), the extremely wet days (R99P), the maximum 1-day precipitation amount (RX1day) and the maximum 5-day precipitation amount (RX5day). The category 2 is the number of heavy precipitation days (R10day), the number of very heavy precipitation days (R20day) and the simple daily intensity index (SDII). The category 3 and 4 is the consecutive wet days (CWDday) and the consecutive dry days (CDDday), respectively. For the extreme precipitations in the category 1, the abrupt change point from less to more values occurs in 1991 in summer. Three abrupt change points, from less to more in 1972 and 2009, and from more to less in 1994 occur in spring. For the extreme precipitations in the category 2, the abrupt change point from less to more values occurs in 1993 in summer. Three abrupt change points, from less to more in 1965 and 2010, and from more to less in 1990 occur in spring. Annually and seasonally, the abrupt changes occur in early 2010s for CWDday which has clearly been more and for CDDday which has clearly been less. In addition, CWDday occurs abrupt change points from less to more in 1966 and from more to less in1983 in spring. The variations of these extreme precipitations have significant periodic oscillations of 3-5 years, quasi-8 years or 8-14 years.

During 1961-1994, 1995-2009 and 2010-2018 three stages, the changes of the annual and most seasonal R95P, R99P, R10day, R20day and SDII are consistent with those of precipitation. The values in the latter stage are increasing compared with those in the former stage. The changes of RX1day, RX5day, CWDday and CDDday have their own characteristics.

\section{Introduction}

It is certain that global mean surface temperature has increased since the late 19th century and the first decade of the $21 \mathrm{st}$ century has been the warmest (Stocker et al, 2013). Previous assessments have already shown that precipitation extremes appear to have increased in more regions than they have decreased (Alexander, 2016). Temperature extremes show consistent warming trends globally and in most land areas over the past century. Besides, precipitation extremes show global tendencies toward more intense rainfall throughout much of the twentieth century (Donat et al., 2016). Precipitation extremes show increasing trends in large parts of Eurasia, North Australia, and the Midwestern United States during the 1964-2013 period (Papalexiou et al., 2019). Zhang and Zhou (2019) have found significant increases in the annual maximum daily precipitation and associations with global warming in regional monsoon domains, including the southern part of the South African monsoon region, the South Asian monsoon region, the North American monsoon region, and the eastern part of the South American monsoon region during 1901-2010.

In China, rainstorms or extreme precipitation events are insignificantly increasing as a whole during the past more than 50 years (Ren et al., 2010). However, extreme precipitation and wet days exhibit an increasing trend, and the maximum number of consecutive dry days shows a tendency toward shorter duration in over the Arid Region of Northwestern China (Wang et al., 2017). The number of days of extreme precipitation in the northwest of China has the obvious increase (Li et al., 2020). The frequency and amount of extreme precipitation increased in South China, Southeast Asia and North China while have a decreasing trend in Yangtze River basin (Sun and Zhang et al, 2017; Cui et al., 2019; Wang et al.,2020). There were three periods with highly frequent precipitation extremes since 1960: early 1960s, middle and late 1990s, and early 21st century (Sun and Zhang, 2017). The frequency of extreme precipitation events has been decreasing during the past 48 years in the upper of the Yellow River Basin (Ma and Gao, 2019). The regionally averaged daily rainfall intensity exhibits significant decreases, whereas consecutive dry days significantly increase, but the changes in days of erosive rainfall, heavy rain, rainstorm, maximum5-day precipitation, and very-wet-day and extremely wet-day precipitation are not significant during 1960-2013 in the Loess Plateau in China (Sun et al., 2016). Southwestern China has generally become drier and experienced enhanced precipitation extremes in the past 60 years (Liu et al., 2014, 2015). Wang et al. (2017) analyzed twelve indices of extreme precipitation over Northeast China and found that the consecutive dry days decreased significantly while the other precipitation indices didn't have significant decreasing trends. The light rain events display a decreasing trend in summer and winter half years over East China and an increasing trend in winter half years over Northwest China (Huang and Wen, 2013). The spatial distribution of summer extreme precipitation events demonstrates remarkable regional differences and an increasing trend is found in the middle and lower

Page 2/18 
reaches of the Yangtze River, South China, and Northwest China, while a decreasing trend occurs in Northeast China, North China, and part of Southwest China (Long et al., 2016). But, Zeng and Lu (2015) concluded that the rainfall of summer extreme precipitation was increasing over the South China and decreasing over the North China. Lu et al. (2020) concluded that the increasing trends of extreme precipitation amounts and days mainly located in the southeastern coastal and Western China.

Guangdong-Hong Kong-Macao Greater Bay Area (GBA) is a city cluster that consists of the Hong Kong and Macao special administrative regions and the cities of Guangzhou, Shenzhen, Zhuhai, Foshan, Zhongshan, Dongguan, Huizhou, Jiangmen and Zhaoqing in the Pearl River Delta region in South China. It is the 4th largest bay area in the world after the New York Bay Area, San Francisco Bay Area and Tokyo Bay Area. Its population reached 69.57 million in 2017and it is crucial to enhancing China's social and economic progress in the near future. The situation and trend of extreme climate are of great significance to the formulation of disaster prevention and mitigation and sustainable development policy in GBA.

In South China, there is spatial disparity in trend magnitudes of extreme precipitation indices, and approximate $60.85 \%, 75.32 \%$ and $75.74 \%$ of the grid boxes show increasing trends for the maximum 5-day precipitation (RX5day), simple daily intensity index (SDII) and very wet day precipitation (R95), respectively (Ren et al., 2015). The consistent anomaly distribution is the main type of extremely heavy precipitation and the extremely heavy precipitation events are less frequent in the 1960s and 1980s, while an increasing trend from the late 1980s exist in South China (Lu et al., 2012). The wet day precipitation, consecutive wet days and numbers of heavy precipitation days exhibit non-significant decreasing trends. The consecutive dry days and simple daily intensity index have significantly increased, while other extreme precipitation indexes have non-significant increasing trends in the Pearl River Basin in South China (Zhao et al., 2014). Summer extreme precipitation has undergone the significant increase in South China after 1992/1993 and played important roles in the corresponding summer total precipitation variations (Li et al., 2016). The extreme heavy precipitation is significantly increasing during the pre-flood season since the 1990 s and the drought and flood disasters have increased since 1993 during the post-flood season in South China (Li et al., 2010, 2012). The extreme precipitation indexes have a significant inter-annual periodic variation with 3-5years and 6-8 years in the pre-flood season and the post-flood season, respectively, and increasing slightly (Cai et al., 2018).

To sum up, variations of extreme precipitation are different with seasons and regions. There are similarities and differences between different types of extreme precipitation. Some conclusions are still vague and contradictory, and the study of extreme precipitation in China needs to be further improved. At present, scholars pay more attention to the changes of extreme temperature events and typhoons on the coast of South China, but the analysis of the variations of extreme precipitation events on the coast of South China is not sufficient. This paper will compare and analyze variations of the precipitation extremes over GBA in China and reveal the characteristics of extreme precipitation under global warming. Also, providing scientific basis for relevant departments to deal with climate change.

\section{Data And Methods}

The gridded $0.25^{\circ} \times 0.25^{\circ}$ observation dataset of CN05.1 provided by the China Meteorological Administration is used in this study, including daily temperatures and precipitation during the period 1961-2018. This homogenized high-resolution data set is based on interpolation from 2416 station observations with quality control measures applied, such as deleting outliers that are far different from the actual climate state and surrounding meteorological stations (Wu and Gao, 2013). The data set has been widely used to quantify precipitation extremes (Wang et al., 2017).

The CN05.1 dataset was constructed from observations at 2400 stations across China, and interpolated by the 'anomaly approach', i.e., a gridded climatology was first calculated, and then a gridded daily anomaly was added to the climatology to produce the final dataset (Wu and Gao,2013; Wang et al, 2017) $\square$

In this paper, a rectangular area of $(21.5 \square \mathrm{N}-24.5 \square \mathrm{N}, 111.5 \square \mathrm{E}-115.5 \square \mathrm{E})$ is used as GBA (see Fig. 1 the red box area), which includes the main body of GBA and its surrounding areas. Figure 1 shows spatial distribution of the trends for annual mean air temperature and annual total precipitation during 1961-2018 in China. The warming trend in China all passes the significance test of confidence level $a=0.05$, and the most significant warming is in the western and northern regions of China. Compared with the warming trend in China, GBA is a relatively significant region. The most significant increase of precipitation in China is in

Page 3/18 
the middle and lower reaches of the Yangtze River and the coastal areas of South China. The increase of precipitation in the vast areas of Northwest China and the southern part of Northeast China also passes the significance test $(a=0.05)$. The precipitation has increased in GBA, which is one of the most significant areas in China.

Up to now, there are many definitions of extreme precipitation, and most literatures use the extreme climate indices defined by the Expert Team on Climate Change Detection and Indices (ETCCDI, Zhang et al, 2011). In this study, we analyze characteristics of precipitation extremes using nine basic indices of ETCCDI. They are: 1) R99P (Extremely wet days): total precipitation when the daily precipitation > 99th percentile of 1961-2018 daily precipitation (unit: $\mathrm{mm}$ ). 2) R95P (Very wet days): total precipitation when the daily precipitation > 95th percentile of 1961-2018 daily precipitation (unit: mm). 3) RX1day (Maximum 1-day precipitation amount): maximum 1-day precipitation (unit: $\mathrm{mm}$ ). 4) RX5day (Maximum 5-day precipitation amount): maximum consecutive 5day precipitation (unit: $\mathrm{mm}$ ). 5) R10day (Number of heavy precipitation days): count of days when the daily precipitation $\geq 10$ $\mathrm{mm}$ (unit: day). 6) R20day (Number of very heavy precipitation days): count of days when the daily precipitation $\geq 10 \mathrm{~mm}$ (unit: day). 7) SDII (Simple daily intensity index): average precipitation on wet days (unit: $\mathrm{mm}$ ). 8) CWDday (Consecutive wet days): Maximum number of consecutive wet days when the daily precipitation $\geq 1.0 \mathrm{~mm}$ (unit: day). 9) CDDday (Consecutive dry days): Maximum number of consecutive dry days when the daily precipitation $<1.0 \mathrm{~mm}$ (unit: day).

We calculate annual and seasonal regional mean values of air temperature (TM), precipitation (PRE) and nine precipitation extreme indices over GBA from 1961 to 2018. Winter (DJF) refers to December of the previous year to February of the current year, Spring (MAM) refers to march to May of the current year, Summer (JJA) refers to June to August of the current year, and autumn (SON) refers to September to November of the current year. Due to the lack of value in December of previous year, for the average variable, the DJF value of 1961 is the mean of January to February of 1961; for the cumulative variable, the DJF value of 1961 is 3 times the mean of January to February. The linear regression is used to assess trends. T-test is used to test the significance and we use $a=0.05$ to determine whether the trend is statistically significant. The Mann-Kendall method (Goossens and Berger, 1986; McLeod et al., 1991) is used to detect abrupt changes. The MK test has been widely used to detect the significance of abrupt changes and locate the approximate change point of any potential trend in the anomalies. UF and UB are the forward and backward sequential statistics, respectively. The intersection of UF and UB curves denotes the approximate beginning of the trend. In this work, UF and UB were calculated according to the equations introduced by Zhang et al. (2014). Besides, the Morlet wavelet analysis (Torrence and Compo, 1998) is used to study inter-annual oscillations and the wavelet powers and their significances are analyzed. Wavelet software is provided by C. Torrence and G. Compo, and is available at the URL: http://paos.colorado.edu/research/wavelets/. Finally, the responses of extreme precipitation to abrupt climate change are analyzed and discussed.

\section{Results}

\subsection{Variation characteristics of various extreme precipitation}

Table 1

Climatic inclinations of the regional average annual and seasonal extreme precipitations in GBA from 1961 to 2018

\begin{tabular}{|c|c|c|c|c|c|c|c|c|c|c|c|}
\hline & TM & PRE & R95P & R99P & RX1day & RX5day & R10day & R20day & SDII & CWDday & CDDday \\
\hline unit & ${ }^{\circ} \mathrm{Ca}^{-1}$ & $\mathrm{mma}_{1}^{-}$ & $\mathrm{mma}_{1}^{-}$ & $\mathrm{mma}_{1}^{-}$ & $\mathrm{mma}^{-1}$ & $\mathrm{mma}^{-1}$ & daya $^{-1}$ & daya $^{-1}$ & $\mathrm{mma}_{1}^{-}$ & daya $^{-1}$ & daya $^{-1}$ \\
\hline annual & $0.021 *$ & $5.517 *$ & 1.716 & 0.366 & 0.066 & 0.388 & $0.154 *$ & $0.073^{*}$ & 0.003 & 0.050 * & $-0.083^{\star}$ \\
\hline DJF & $0.027 *$ & 0.972 & 0.517 & 0.246 & 0.196 & 0.442 & 0.020 & 0.015 & 0.007 & 0.025 & -0.078 \\
\hline MAM & $0.016^{*}$ & 1.928 & 0.349 & -0.145 & 0.008 & -0.128 & 0.045 & 0.021 & -0.005 & $0.072^{\star}$ & $-0.055^{\star}$ \\
\hline JJA & $0.015^{\star}$ & $2.515^{\star}$ & $1.018 *$ & $0.632 *$ & 0.120 & $0.589 *$ & $0.086 *$ & $0.039 *$ & $0.023 *$ & 0.009 & -0.032 \\
\hline SON & $0.026 *$ & 0.126 & -0.169 & -0.367 & -0.025 & 0.012 & 0.003 & -0.002 & -0.005 & 0.024 & -0.037 \\
\hline
\end{tabular}


Climatic inclinations of the regional average annual and seasonal extreme precipitations in GBA from 1961 to 2018 are investigated in Table 1. Trends and variations of these regional extreme precipitation anomalies are shows in Figs. 2, 3 and 4. We find that the trends of R95P and RX1day are negative in SON, positive in DJF, MAM and JJA. Differently, the trend of RX5day is negative in MAM and positive in DJF, JJA and SON. The trend of R99P is negative in MAM and SON, and positive in DJF and JJA. The confidence levels for R95P, R99P and RX5day reach a significant level of $a=0.05$ only in JJA. The trends of R10day and R20day are positive except in SON. The confidence levels for R10day and R20day reach a significant level of $a=0.05$ in JJA. The trend of SDII is negative in MAM and SON, and positive in DJF and JJA. The confidence level for SDII reaches a significant level of $a=0.05$ only in JJA. The trends of CWDday (CDDday) are positive (negative) in all seasons, and the confidence levels reach a significant level of $a=0.05$ in spring. In general, R95P, R99P, RX5day, R10day, R20day and SDIl have a significant increasing trend in summer, while RX1day, CWDday and CDDday have no obvious trends. In spring, CWDday increases significantly, but CDDday decreases significantly, and there is no significant trend for other extreme precipitation. In winter and autumn, the nine indices all have no significant trends. Annually, R10day, R20day and CWDday have significant increasing trends, CDDday has a significant decreasing trend, but R95P, R99P, RX1day, RX5day and SDIl have no significant trends.

Annually, the trend and inter-annual variation of R95P are basically consistent with that of R99P, RX1day and RX5day (Fig. 2a, b, C, d). The characteristics for these 4 kinds of extreme precipitation are also basically consistent in DJF (Fig. 2e, f, g, h), MAM (Fig. 2i, j, k, I), JJA (Fig. 2m, n, o, p), and SON (Fig. 2q, r, s, t), respectively. The correlation coefficients of R95P and R99P in the annual, DJF, MAM, JJA and SON are 0.95, 0.99, 0.93, 0.95 and 0.92, respectively. And then, the correlation coefficients of R95P and RX1day in the annual, DJF, MAM, JJA and SON are $0.64,0.90,0.81,0.82$ and 0.87 , respectively. Also, the correlation coefficients of R95P and RX5day in the annual, DJF, MAM, JJA and SON are $0.65,0.91,0.82,0.82$ and 0.90 , respectively. All of these coefficients pass the statistical test with a significant level of $a=0.001$. These 4 kinds of extreme precipitation are classified into the same category and represented by R95P which will be detected abrupt changes and inter-annual oscillations.

The trend and inter-annual variation of annual R20day are basically consistent with that of annual R10day and SDII (Fig. 3a, b, c). Also, the characteristics for these 3 kinds of extreme precipitation are also basically consistent in DJF (Fig. 3d, e, f), MAM (Fig. 3g, h, i), JJA (Fig. 3j, k, I), and SON (Fig. 3m, n, o), respectively. The correlation coefficients of R20day and R10day in the annual, DJF, MAM, JJA and SON are $0.93,0.94,0.95,0.92$ and 0.93 , respectively. And the correlation coefficients of R20day and SDII in the annual, DJF, MAM, JJA and SON are $0.73,0.91,0.83,0.91$ and 0.77 , respectively. All of these coefficients also pass the statistical test with a significant level of $a=0.001$. These 3 kinds of extreme precipitation are classified into the same category and represented by R20day which will be detected abrupt changes and inter-annual oscillations.

The variations of CWDday and CDDday (Fig. 4) show their own characteristics and may not be classified into the above two categories. Their abrupt changes and inter-annual oscillations will be detected respectively.

Figure 5 shows the results of the Mann-Kendall abrupt change tests for the regional average annual and seasonal R95P, R20day, CWDday and CDDday in GBA. UF and UB are the forward and backward sequential statistics, respectively. The intersection of UF and UB curves denotes the abrupt change point. If the UF and UB curves are entangled and there is no obvious distance, the intersection points are not considered as abrupt change points. The null hypothesis is rejected when any of the points exceeds the confidence interval \pm 1.96 that denotes a $a=0.05$ confidence level. In JJA, the abrupt changes from less to more values can be seen in 1991 for R95P and in 1993 for R20day; R95P (R20day) has clearly been higher since 1991 (1993). In MAM, R95P shows three abrupt change points, from less to more in 1972 and 2009, and from more to less in 1994; R20day shows three abrupt change points, from less to more in 1965 and 2010, and from more to less in 1990. In DJF and SON, R95P and R20day show no obvious abrupt change points. Annual R95P and R20day show also no obvious abrupt change points. Annually and seasonally, the abrupt change can be seen in early 2010s for CWDday which has clearly been more and for CDDday which has clearly been less; in addition, CWDday in MAM occurs abrupt change points from less to more in 1966 and from more to less in1983.

Figure 6 shows the Morlet wavelet analysis of the regional average annual and seasonal R95P, R20day, CWDday and CDDday in GBA. Annually and seasonally, the variations of R95P have a significant periodic oscillation of 3-5 years, which is relatively significant in DJF and MAM during 1980-1990s, in JJA during 2000s, and in SON during 1960s, 1980-1990s and 2010s; the variations of R95P also have a significant periodic oscillation of 8-14 years, which is relatively significant in JJA and SON. The variations of R20day have a significant periodic oscillation of 3-5 years, which is relatively significant in DJF during 1980-1990s, 
in MAM during 1960-1070s, in JJA during 1960s, 1990-2000s, and in SON during 1960s, 1980-1990s and 2010s. The variations of CWDday have a significant periodic oscillation of 3-5 years, which is relatively significant in DJF during 1980-1990s, in MAM during 1070s, in JJA during 1960s, 1990-2000s, and in SON during 1970s. The variations of CDDday have a significant periodic oscillation of 3-5 years, which is relatively significant in all period in DJF, in MAM during 1070s, in JJA durng 1960s, 1980-1990s, and in SON during 1960s. The variations of CWDday and CDDday also have both a significant periodic oscillation of quasi-8 years.

\subsection{Response of extreme precipitation to abrupt climate change}

The annual and seasonal average temperatures show increasing trends in GBA (Fig. 7a, c, e, g, i). Climatic inclinations of the annual, DJF, MAM, JJA and SON average temperatures are $0.021^{\circ} \mathrm{Ca}^{-1}, 0.027^{\circ} \mathrm{C} \mathrm{a}^{-1}, 0.016^{\circ} \mathrm{Ca}^{-1}, 0.015^{\circ} \mathrm{Ca}^{-1}$ and $^{-1} .026^{\circ} \mathrm{Ca}^{-}$

1 , respectively (Table 1). Their confidence levels all reach a significant level of $\mathrm{a}=0.05$. The warming trend is the most obvious in winter and the weakest in summer. In GBA, the abrupt warming change occurs in 1995, 1989, 1998, 1995 and 1997 for the annual, DJF, MAM, JJA and SON, respectively (Fig. $7 b, d, f, h, j)$. The mutation is the earliest in DJF and the latest in MAM.

The average annual and seasonal precipitations show increasing trends in GBA (Fig. 8a, c, e, g, i). Climatic inclinations of the annual, DJF, MAM, JJA and SON precipitations are $5.517 \mathrm{mma}^{-1}, 0.972 \mathrm{mma}^{-1}, 1.928 \mathrm{mma}^{-1}, 2.515 \mathrm{mma}^{-1}$ and $^{-1} .126 \mathrm{mma}^{-1}$, respectively (Table 1). The confidence levels reach a significant level of $a=0.05$ only in MAM and in annual. For the average precipitation in GBA, the abrupt changes from less to more values can be seen in 2012 in annual, DJF and MAM, and in 1993 in JJA; in addition, the abrupt changes from less to more in 1968 and from more to less in 1991 can be seen in MAM (Fig. 8b, d, f, h, j).

In summary, annually and seasonally, the abrupt warming changes of the average temperature in GBA occur around 1995. The abrupt increasing change of the average precipitation occur in 1993 for JJA, in 2012 for DJF, MAM and annual. The analysis in the 3.1 section shows that most of the abrupt changes of extreme precipitations occur in the early 1990s and around 2010. Based on the main abrupt change characteristics of temperature, precipitation and extreme precipitations, we divide the extreme precipitation change into three stages: 1961-1994, 1995-2009 and 2010-2018, to compare and analyze the difference of average values of extreme precipitations, and to determine the response degree of extreme precipitations to climate change.

Figure 9 shows changes of climate and extreme precipitations in GBA during three different stages. During 1961-1994, the annual, DJF, MAM, JJA and SON average temperatures are $20.4{ }^{\circ} \mathrm{C}, 12.4^{\circ} \mathrm{C}, 20.5^{\circ} \mathrm{C}, 26.9^{\circ} \mathrm{C}$ and $21.8^{\circ} \mathrm{C}$, respectively. During $1995-2009$, these values are $20.4^{\circ} \mathrm{C}, 12.4^{\circ} \mathrm{C}, 20.2{ }^{\circ} \mathrm{C}, 27.0^{\circ} \mathrm{C}$ and $21.7^{\circ} \mathrm{C}$, respectively. There are little changes during $1961-$ 1994 and $1995-2009$ stages. But, during $2010-2018$, these values are $21.1{ }^{\circ} \mathrm{C}, 13.4{ }^{\circ} \mathrm{C}, 20.9{ }^{\circ} \mathrm{C}, 27.4{ }^{\circ} \mathrm{C}$ and $22.6^{\circ} \mathrm{C}$, respectively, which are $0.7^{\circ} \mathrm{C}, 1.0^{\circ} \mathrm{C}, 0.7{ }^{\circ} \mathrm{C}, 0.4^{\circ} \mathrm{C}$ and $0.9^{\circ} \mathrm{C}$ higher than those during $1961-1994$. In recent decades, the warming of temperature in GBA is mainly manifested after 2010 , with the most obvious in DJF and SON.

The annual, DJF, MAM, JJA and SON average precipitations are $1811.2 \mathrm{~mm}, 149.6 \mathrm{~mm}, 581.2 \mathrm{~mm}, 791.0 \mathrm{~mm}$ and $297.7 \mathrm{~mm}$, respectively during $1961-1994 ; 1874.1 \mathrm{~mm}, 164.3 \mathrm{~mm}, 700.0 \mathrm{~mm}, 729.9 \mathrm{~mm}$, and $288.5 \mathrm{~mm}$ during 1995-2009, respectively; $1966.2 \mathrm{~mm}, 184.9 \mathrm{~mm}, 635.2 \mathrm{~mm}, 865.6 \mathrm{~mm}$ and $289.4 \mathrm{~mm}$ during $2010-2018$, respectively. The annual and DJF precipitations in the latter stage are increasing compared with those in the former stage and have increased $155.0 \mathrm{~mm}$ and $25.3 \mathrm{~mm}$ during 2010-2018 than 1961-1994, respectively. The SON precipitation has little changes in the three stages and 2010-2018 is only $8.3 \mathrm{~mm}$ less than 1961-1994. The MAM precipitation increases significantly during 1995-2009, and decreases during 20102018 , but the general trend is increasing. The MAM precipitation during $2010-2018$ is $54.0 \mathrm{~mm}$ more than 1961-1994. The JJA precipitation decreases during 1995-2009, but increases significantly during 2010-2018. The JJA precipitation during 20102018 is $74.6 \mathrm{~mm}$ more than $1961-1994$.

The average annual, DJF, MAM, JJA and SON values account for $28.3 \%, 31.2 \%, 28.1 \%, 25.4 \%$ and $34.3 \%$ of the total precipitation for R95P, respectively; $15.8 \%, 15.7 \%, 12.8 \%, 11.4 \%$ and $17.0 \%$ of the total precipitation for R99P, respectively. Changes of annual and most seasonal R95P and R99P are consistent with those of precipitation, but the annual R99P is the most during 19952009. The average annual, DJF, MAM, JJA and SON values during $2010-2018$ are $58.8 \mathrm{~mm}, 16.4 \mathrm{~mm}, 11.2 \mathrm{~mm}, 33.4 \mathrm{~mm}$ and 2.4mm more than 1961-1994 for R95P, respectively; $10.5 \mathrm{~mm}, 8.3 \mathrm{~mm},-6.0 \mathrm{~mm}, 14.7 \mathrm{~mm}$ and $-6.4 \mathrm{~mm}$ more during 2010-2018 
than 1961-1994 for R99P, respectively. The annual and seasonal R99P and R95P are increasing except for R95P in MAM and SON and R99P in SON.

The changes of the annual and seasonal R10day, R20day and SDII are consistent with those of precipitation, except for MAM SDII. The values in the latter stage are increasing compared with those in the former stage. The average R10day, R20day and SDII during 2010-2018 are 5.0day, 2.3day and 0.1 mm more than 1961-1994 in annual, respectively; 1.1day, 2010-2018 are 0.6day and 0.6mm more than 1961-1994 in DJF, respectively. In SON, the average values in three stages are basically unchanged for R10day, R20day and SDII. In MAM, R10day, R20day and SDII all increase significantly during 1995-2009, and decreases during 2010-2018; the general trend is increasing for R10day and R20day, and decreasing slightly for SDIl; the average R10day and R20day during 2010-2018 are 1.5day and 0.7day more than 1961-1994, respectively; but the average SDII during 2010-2018 is $0.2 \mathrm{~mm}$ less than 1961-1994. In JJA, the average values are decreasing slightly during 1995-2009 and increasing significantly during 2010-2018 for R10day, R20day and SDIl; the average R10day, R20day and SDII during 2010-2018 are 2.8day, 1.3day and $0.8 \mathrm{~mm}$ more than $1961-1994$, respectively.

The changes of RX1day and RX5day have their own characteristics, which are affected by both temperature and precipitation. The annual RX1day shows a slight decrease that is only $1.0 \mathrm{~mm}$ less during 2010-2018 than 1961-1994. But, the annual RX5day shows a significant increase that is 6.6mm more during 2010-2018 than 1961-1994. In DJF, RX1day and RX5day have same characteristic with precipitation and both of them increase in the latter stage compared with the former stage; the average RX1 day and RX5day during 2010-2018 are 4.9mm and 13.3mm more than 1961-1994, respectively. In MAM, RX1day and RX5day in the latter stage are decreasing compared with those in the former stage; the average RX1day and RX5day during 2010-2018 are 3.6mm and 26.5mm less than 1961-1994, respectively. In JJA, the RX1day and RX5day have same characteristic with precipitation and are slightly decreasing during 1995-2009 and significantly increasing during 2010-2018; the average RX1day and RX5day during 2010-2018 are 1.2mm and 16.5mm more than 1961-1994, respectively. In SON, the average values are also basically unchanged in three stages for RX1day, but slightly increasing in the latter stage compared with the former stage for RX5day; the average RX5day during 2010-2018 is 4.5mm more than 1961-1994.

In DJF, MAM and SON, the changes of the CWDday are consistent with those of precipitation and the values are increasing in the latter stage compared with the former stage. The average CWDday during 2010-2018 are 1.1day, 1.6day and 0.4day more than 1961-1994 in DJF, MAM and SON, respectively. In JJA, the average CWDday is decreasing significantly during 1995-2009 and increasing significantly during 2010-2018; the general trend is to decrease; the average CWDday during 2010-2018 is 0.6day less than 1961-1994. The average annual CWDday is also decreasing significantly during 1995-2009 and increasing significantly during 2010-2018; but the general trend is upward; the average annual CWDday during 2010-2018 is 0.5day more than 1961-1994.

Annually and seasonally, the average values of CDDday are the highest during 1995-2009, except MAM. The average annual CDDday in 2010-2018 is 1.3day less than 1961-1994. In DJF and JJA, the average CDDday is increasing during 1995-2009 and decreasing during 2010-2018; the general trend is decreasing. The average CDDday during 2010-2018 is 0.8day and 0.7day less than 1961-1994 in DJF and JJA, respectively. In MAM, the value of the CDDday is decreasing in the latter stage compared with the former stage; the average CDDday during 2010-2018 is 2.3day less than 1961-1994. In SON, the average CDDday is increasing during 1995-2009 and decreasing during 2010-2018; the general trend is increasing; the average CDDday is 0.2day more in 2010-2018 than 1961-1994.

\section{Conclusions And Discussions}

1) During the period of 1961-2018, compared with the warming trend in China, GBA is a relatively significant region. The precipitation has increased significantly in GBA, which is one of the most significant areas in China. The warming of temperature in GBA is mainly manifested after 2010, with the most obvious in winter and autumn. Annually and seasonally, the abrupt warming changes of the average temperature occur around 1995. The abrupt increasing change of the average precipitation occur in 1993 or 2012. 
2) In summer, R95P, R99P, RX5day, R10day, R20day and SDIl have a significant increasing trend, while the changes of RX1day, CWDday and CDDday have no obvious trend. In spring, CWDday increases significantly, CDDday decreases significantly, and there was no significant trend for other extreme precipitations. In winter and autumn, the nine indices all have no significant trend. Annually, R10day, R20day and CWDday have significant increasing trends, CDDday has a significant decreasing trend, but R95P, R99P, RX1day, RX5day and SDII have no significant trend.

3) The trends and inter-annual variations of R95P, R99P, RX1day and RX5day are basically consistent. For these extreme precipitations, the abrupt change point from less to more values occurs in 1991 in summer. Three abrupt change points, from less to more in 1972 and 2009, and from more to less in 1994 occur in spring. No obvious abrupt change point occurs in winter and autumn. Annually, no obvious abrupt change point occurs. Besides, the annual and seasonal variations of these extreme precipitations have significant periodic oscillations of 3-5 years and 8-14 years.

4) The trends and inter-annual variations of R10day, R20day, and SDII are basically consistent. For these extreme precipitations, the abrupt change point from less to more values occurs in 1993 in summer. Three abrupt change points, from less to more in 1965 and 2010, and from more to less in 1990 occur in spring. No obvious abrupt change point occurs in winter, autumn and annual. Annually and seasonally, the variations of these extreme precipitations have significant periodic oscillation of 3-5 years.

5) Annually and seasonally, the abrupt changes occur in early 2010s for CWDday which has clearly been more and for CDDday which has clearly been less. In addition, CWDday occurs abrupt change points from less to more in 1966 and from more to less in1983 in spring. The variations of CWDday and CDDday have both significant periodic oscillations of 3-5 years and quasi-8 years.

6) During 1961-1994, 1995-2009 and 2010-2018 three stages, the changes of the annual and most seasonal R95P, R99P, R10day, R20day and SDII are consistent with those of precipitation. The values in the latter stage are increasing compared with those in the former stage. The changes of RX1day, RX5day, CWDday and CDDday have their own characteristics.

China is vigorously building the Guangdong-Hong Kong-Macao Greater Bay Area, and as one of the regions with the most significant increase in precipitation in China, it is necessary to conduct further research on its extreme precipitation. To a certain extent, this paper reveals the annual and seasonal variation characteristics of different types of extreme precipitation in the Guangdong-Hong Kong-Macao Greater Bay Area. On this basis, it is hoped that future research can improve the accuracy of regional precipitation prediction from the perspective of model improvement and integration.

\section{Declarations}

Acknowledgements The authors thank the editor and anonymous reviewers for their careful reviews and valuable comments, which led to substantial improvement of this work. The authors are grateful to China Meteorological Administration for the observation dataset of CN05.1.

Funding statement This work was jointly funded by the National Key R\&D Program of China (2017YFC1502301), the Major projects for talent team introduction of Southern Marine Science and Engineering Guangdong Laboratory (Guangzhou), China (GML2019ZD0601), and the National Natural Science Foundation of China (41875089).

Conflicts of interest The authors declare that they have no conflict of interest.

Authors' contributions Conceptualization: Zhigang Wei; Methodology: Zhigang Wei, Xianru Li; Formal analysis and investigation: Zhigang Wei, Xianru Li; Writing - original draft preparation: Zhigang Wei, Xianru Li; Writing - review and editing: Xianru Li, Huan Wang, Li Ma, Shitong Guo; Funding acquisition: Zhigang Wei

Availability of data and material The gridded $0.25^{\circ} \times 0.25^{\circ}$ observation dataset of CN05.1 provided by the China Meteorological Administration. Wavelet software is provided by C. Torrence and G. Compo, and is available at the URL:

http://paos.colorado.edu/research/wavelets/.

Code availability NCAR Command Language (NCL) were used to process the data process and plot the figures. 
Ethics approval and consent to participate We think ethics approval and consent to participate are not applicable for this study.

Consent for publication The work described has not been published before and also is not under consideration for publication elsewhere.

\section{References}

1. Alexander LV (2016) Global observed long-term changes in temperature and precipitation extremes: A review of progress and limitations in IPCC assessments and beyond. Weather and Climate Extremes 11: 4-16.

https://doi.org/10.1016/j.wace.2015.10.007

2. Cai YX, Lu X, Yang S (2018) Comparison of extreme precipitation events in early and latter rainy seasons over South China. Acta Scientiarum Naturalium Universitatis Sunyatseni 57(1)『83-92. https://doi.org/10.13471/j.cnki.acta.snus.2018.01.012

3. Cui DY, Wang CH, Santisirisomboon J (2019) Characteristics of extreme precipitation over eastern Asia and its possible connections with Asian summer monsoon activity. International Journal of Climatology 39: 711-723.

https://doi.org/10.1002/joc.5837

4. Donat MG, Alexander LV, Herold N, et al (2016) Temperature and precipitation extremes in century-long gridded observations, reanalyses, and atmospheric model simulations. Journal of Geophysical Research: Atmospheres 121(11): 11174-11189. https://doi.org/10.1002/2016JD025480

5. Goossens C, Berger A (1986) Annual and seasonal climatic variations over the Northern Hemisphere and Europe during the last century. Ann Geophys 4: 385-400.

6. Huang G, Wen GH (2013) Spatial and temporal variations of light rain events over China and the mid-high latitudes of the Northern Hemisphere. Chinese Science Bulletin 58: 1402-1411. https://doi.org/10.1007/s11434-012-5593-1

7. Li HX, Chen HP, Wang HJ (2016) Changes in clustered extreme precipitation events in South China and associated atmospheric circulations. International Journal of Climatology 36: 3226-3236. https://doi.org/10.1002/joc.4549

8. Li J, Yan HP, Zhu ZW (2020) Quantitative Analysis of Changes of Summer Extremes Temperature and Precipitation Days over China with Respect to the Mean Temperature Increase. Plateau Meteorology (in Chinese) 39(3):532-542.

9. Li LP, Xu GY, Chen LP, et al (2012) Characteristics of extreme precipitation and its variation trend in the post-flood of South China. Transactions of Atmospheric Sciences (in Chinese) 35 (5):570-577. https://doi.org/10.3969/j.issn.1674-

7097.2012.05.007

10. Li LP, Zhang KM, Wang C, et al (2010) Temporal and spatial variations of extreme precipitation in the pre-flood period of South China in recent 40 years. Climatic and Environment al Research (in Chinese) 15(4):443-450.

11. Liu MX, Xu XL, Sun A, et al (2014) Is southwestern China experiencing more frequent precipitation extremes?, Environmental Research Letters 9 (2014) 064002. https://doi.org/10.1088/1748-9326/9/6/064002

12. Liu MX, Xu XL, Sun A (2015) Decreasing spatial variability in precipitation extremes in southwestern China and the local/large-scale influencing factors. Journal of Geophysical Research Atmospheres 120: 6480-6488. https://doi.org/10.1002/2014JD022886

13. Long YY, Fan GZ, Duan L, et al (2016) A study on the characteristics of summertime extreme precipitation events over China in recent 54 years. Climatic and Environmental Research (in Chinese) 21(4):429-438.

14. Lu H, Chen SR, Guo Y, et al (2012) Spatio-temporal Variation Characteristics of Extremely Heavy Precipitation Frequency over South China in the Last 50 Years. Journal of Tropical Meteorology (in Chinese) 28(2): 219-227. https://doi.org/10.3969/j.issn.1004-4965.2012.02.009

15. Lu S, Hu ZY, Wang BP, et al (2020) Spatio-temporal Patterns of Extreme Precipitation Events over China in Recent 56 Years. Plateau Meteorology (in Chinese) 39(4):683-693.

16. Ma JN, Gao YH (2019) Analysis of annual precipitation and extreme precipitation change in the upper Yellow River Basin in recent 50 years. Plateau Meteorology (in Chinese) 38(1):124-135.

17. McLeod Al, Hipel KW, Bodo BA (1991) Trend analysis methodology for water quality time series. Environmetrics 2 (2): 169200. https://doi.org/10.1002/env.3770020205

Page 9/18 
18. Papalexiou SM, Montanari A (2019) Global and regional increase of precipitation extremes under global warming. Water Resources Research 55: 4901-4914. https://doi.org/10.1029/2018WR024067

19. Ren GY, Feng GL, Yan ZW (2010) Progresses in observation studies of climate extremes and changes in mainland China. Climatic and Environmental Research (in Chinese) 15(4):337-353.

20. Ren ZG, Zhang MG Wang SG, et al (2015) Changes in daily extreme precipitation events in South China from 1961 to 2011. Journal of Geographical Sciences 25(1): 58-68. https://doi.org/10.1007/s11442-015-1153-3

21. Sun J, Zhang FQ (2017) Daily extreme precipitation and trends over China. Science China (Earth Sciences) 60: 2190-2203. https://doi.org/10.1007/s11430-016-9117-8

22. Sun WY, Mu XM, Song XY, et al (2016) Changes in extreme temperature and precipitation events in the Loess Plateau (China) during 1960-2013 under global warming. Atmospheric Research 168: 33-84.

https://doi.org/10.1016/j.atmosres.2015.09.001

23. Song XY, Song SB, Sun WY, et al (2015) Recent changes in extreme precipitation and drought over the Songhua River Basin, China, during 1960-2013. Atmospheric Research 157: 137-152. https://doi.org/10.1016/j.atmosres.2015.01.022

24. Stocker TF, Qin D, Plattner GK, et al (2013) Climate Change 2013: The Physical Science Basis. Contribution of working group I to the fifth assessment report of the intergovernmental panel on climate change. Cambridge University Press, Cambridge, United Kingdom and New York, NY, USA, 1535 pp.

25. Torrence $C$ and Compo GP (1998) A Practical Guide to Wavelet Analysis. Bulletin of the American Meteorological Society 79: 61-78. https://doi.org/10.1175/1520-0477(1998)079<0061:APGTWA>2.0.C0;2

26. Wang CH, Cui DY, Santisirisomboon J (2020) Projected changes in extreme precipitation over Eastern Asia in the 21st century. International Journal of Climatology 40: 3701-3713. https://doi.org/10.1002/joc.6422

27. Wang YJ, Zhou BT, Qin DH, Wu J, et al (2017) Changes in mean and extreme temperature and precipitation over the arid region of northwestern China: Observation and projection. Advances in Atmospheric Sciences 34(3): 289-305. https://doi.org/10.1007/s00376-016-6160-5

28. Wu J, Gao XJ (2013) A gridded daily observation dataset over China region and comparison with the other datasets. Chinese Journal of Geophysics (in Chinese) 56(4): 1102-1111.

29. Zeng YT, Lu E (2015) Changes of Summer Rainfall and Extreme Precipitation During 1961-2010 in China. Climate Change Research (in Chinese) 11(2): 79-85. https://doi.org/10.3969/j.issn.1673-1719.2015.02.001

30. Zhang WX, Zhou TJ (2019) Significant Increases in Extreme Precipitation and the Associations with Global Warming over the Global Land Monsoon Regions. Journal of Climate 32: 8465-8488. https://doi.org/10.1175/JCLI-D-18-0662.1

31. Zhang XB, Alexander L, Hegerl GC, et al (2011) Indices for monitoring changes in extremes based on daily temperature and precipitation data. WIREs Climate Change 2: 851-870. https://doi.org/10.1002/wcc.147

32. Zhang Q, Ye XC, Werner AD, et al (2014) An investigation of enhanced recessions in Poyang Lake: comparison of Yangtze River and local catchment impacts. Journal of Hydrology 517: 425-434. https://doi.org/10.1016/j.jhydrol.2014.05.051

33. Zhao YF, Zou XQ, Cao LG, et al (2014) Changes in precipitation extremes over the Pearl River Basin, southern China, during 1960-2012. Quaternary International 333:26-39. https://doi.org/10.1016/j.quaint.2014.03.060

\section{Figures}


(a)Trend of Annual TM, Prob>95\%

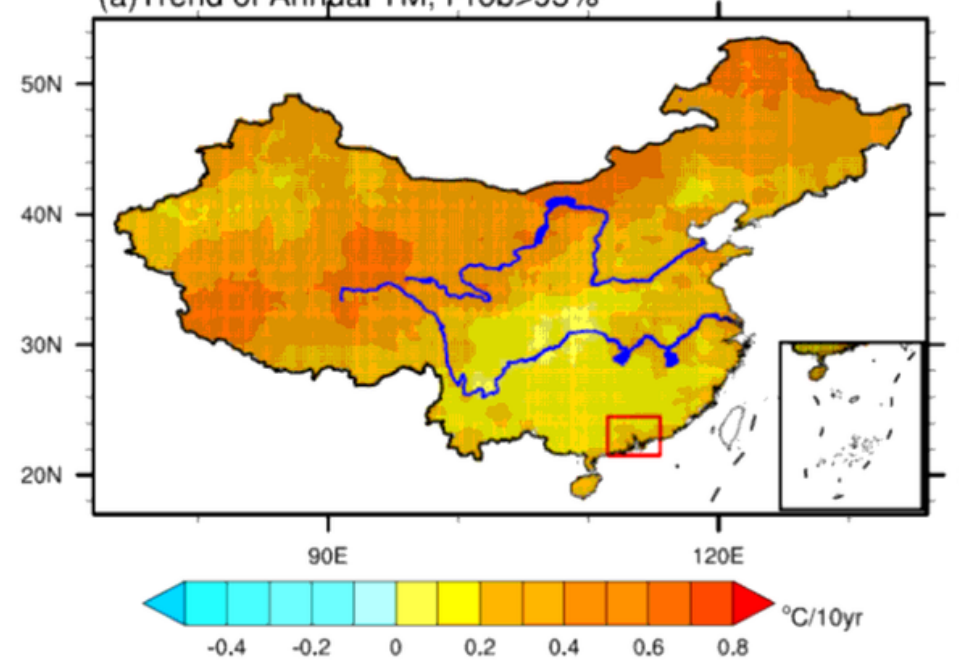

(b) Trend of Annual PRE, Prob $>95 \%$

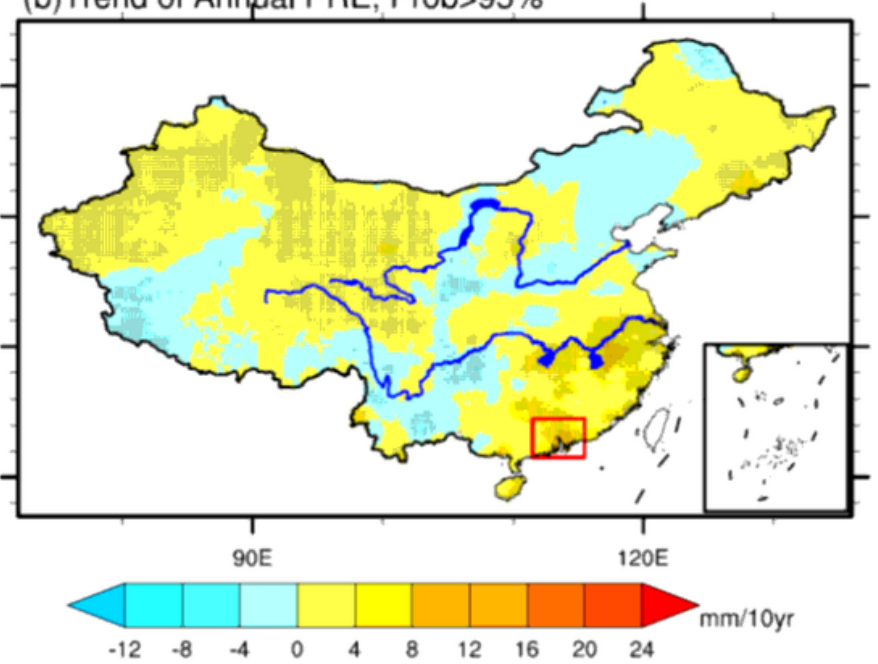

Figure 1

Spatial distribution of the trends for annual mean air temperature (a) and annual total precipitation (b) during 1961-2018. The red box area is GBA. The black dots are the grid points passing the statistical significance test with the confidence level of $a=0.05$.
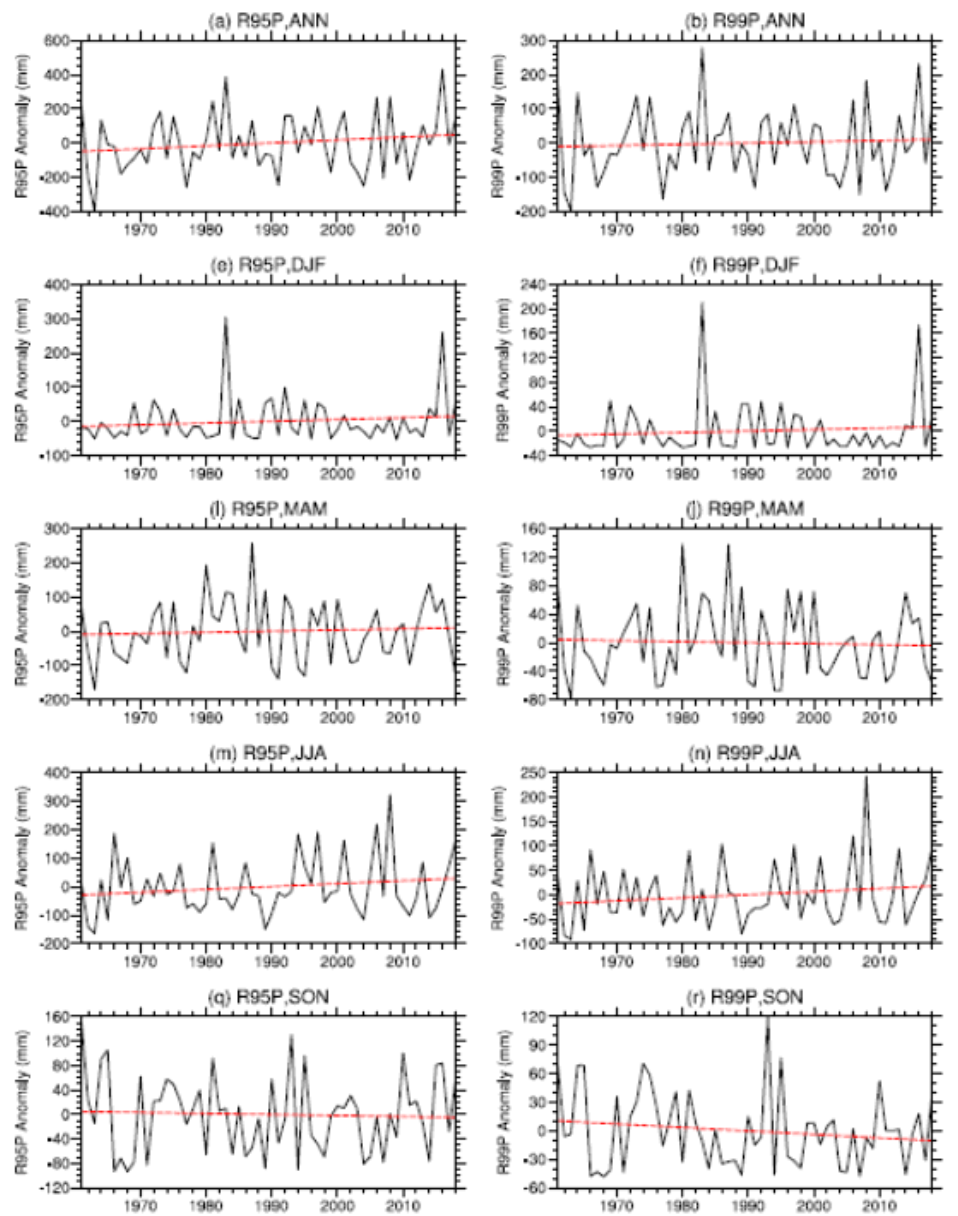
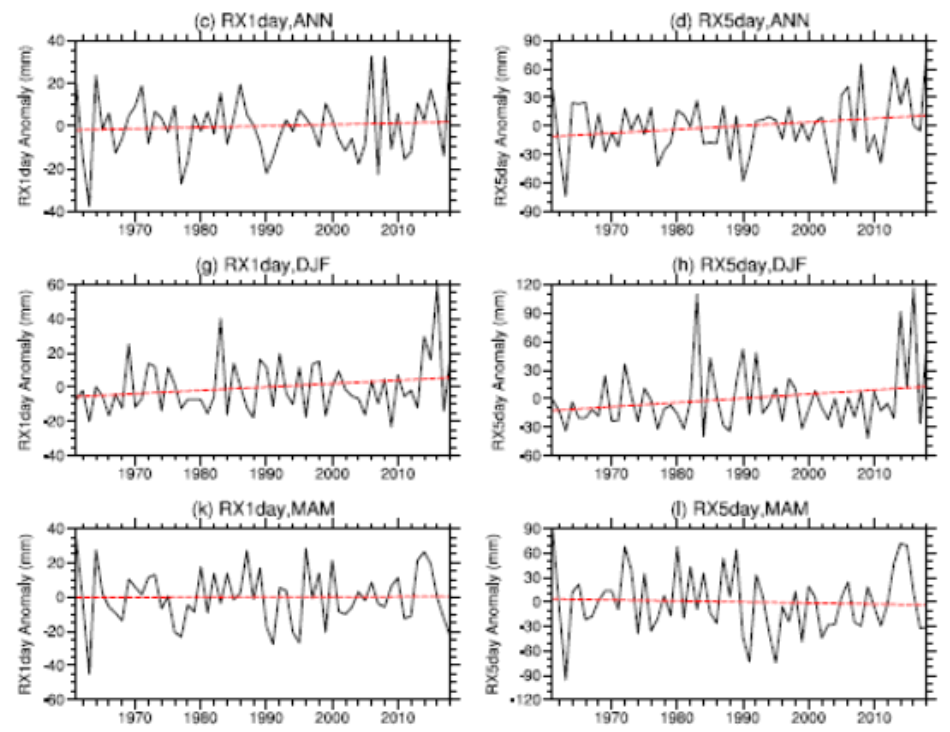

(o) RX1day, JJA

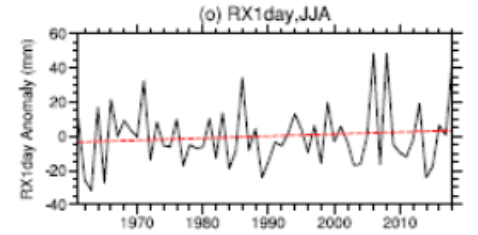

(s) RX1day, SON

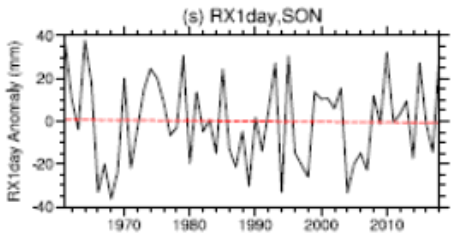

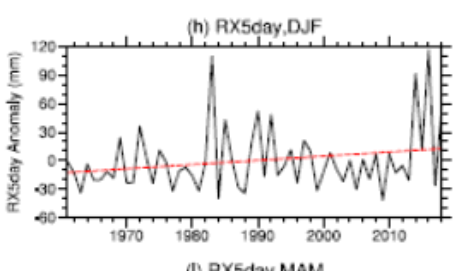

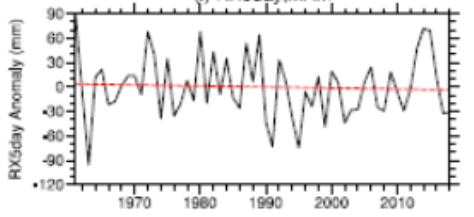

(p) RX5day, JJA

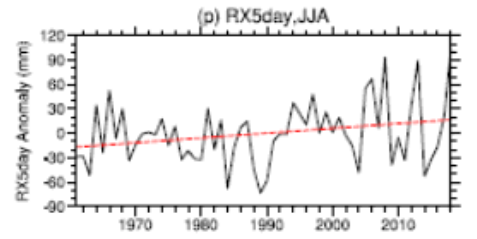

(t) RX5day,SON

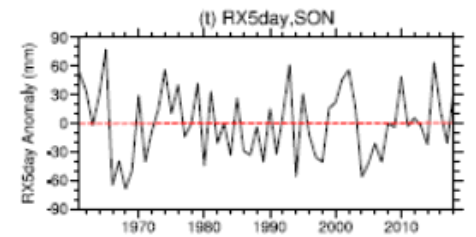

Figure 2 
Variation of the regional average annual and seasonal R95P (a,e,i,m,q), R99P $(b, f, j, n, r), R X 1$ day $(c, g, k, 0, s)$ and RX5day (d,h,l,p,t) anomalies in GBA from 1961 to 2018. The red dashed lines indicate the trends.
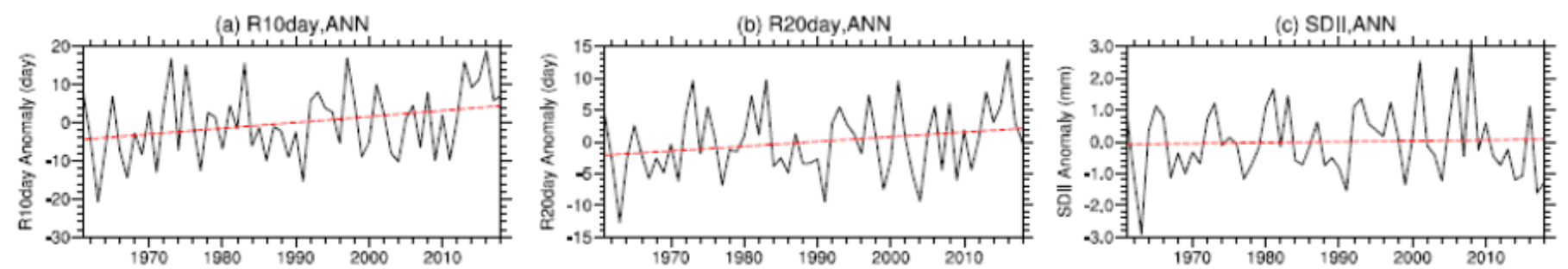

(d) R10day,DJF

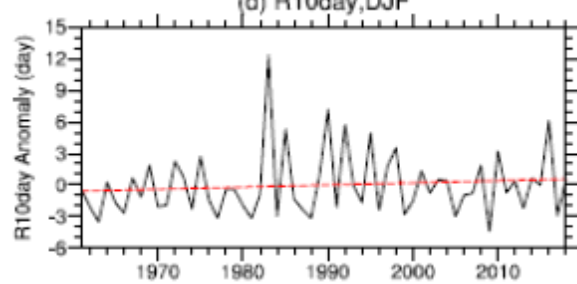

(e) R20day,DJF
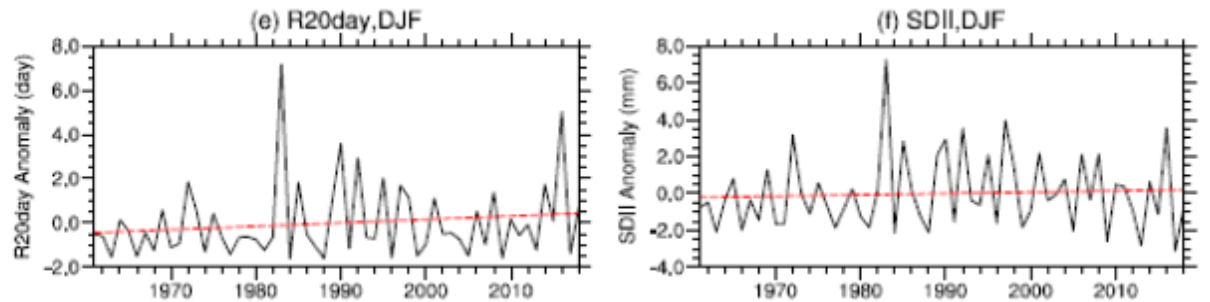

g) R10day,MAM

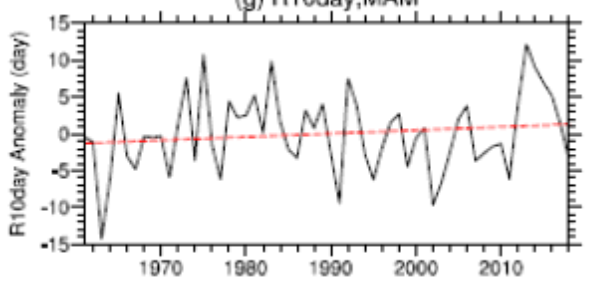

(h) R20day,MAM
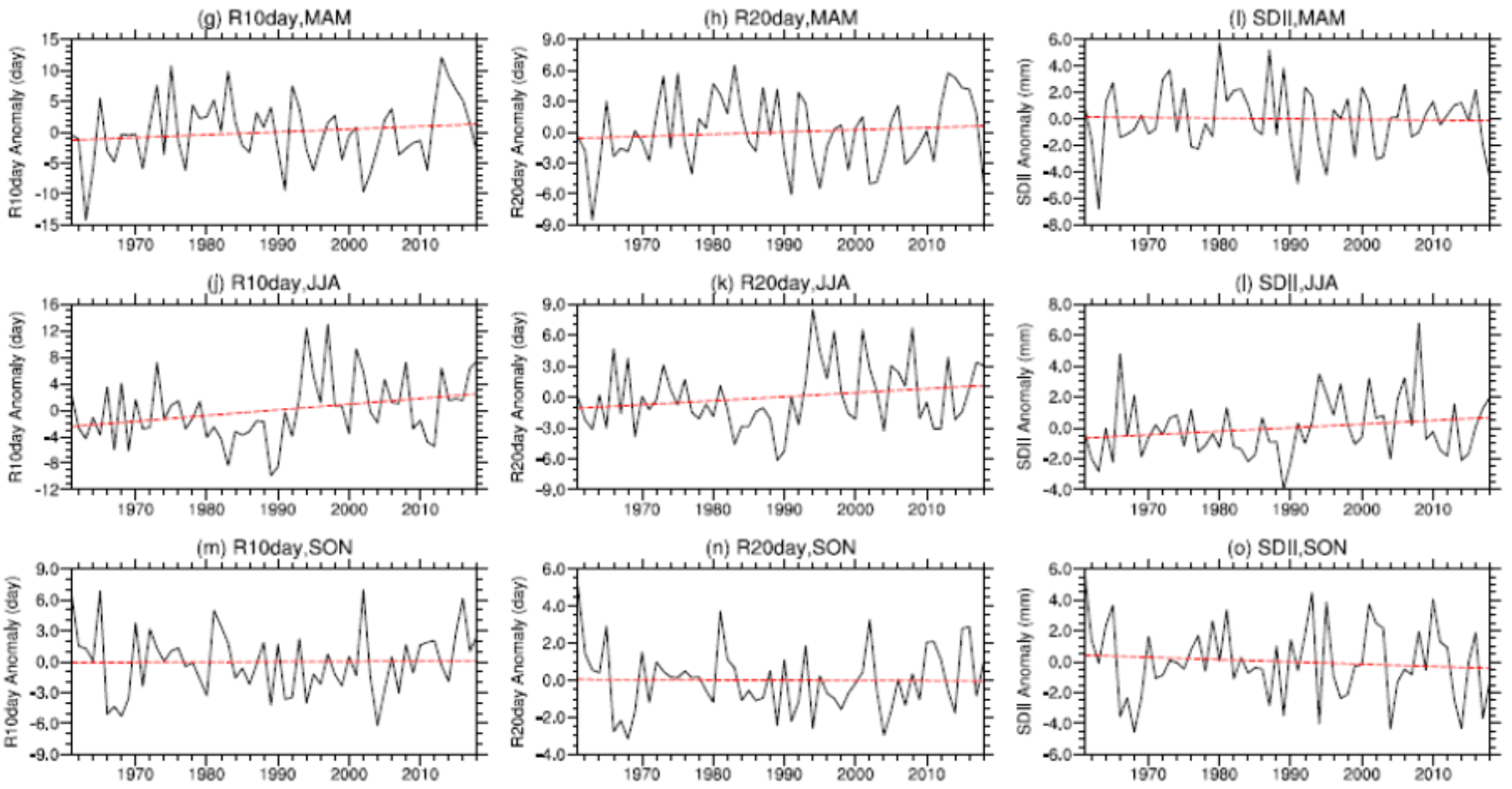

Figure 3

Variation of the regional average annual and seasonal R10day (a,d,g,j,m), R20day (b,e,h,k,n) and SDII (c,g,i,l,o) anomalies in GBA from 1961 to 2018. The red dashed lines indicate the trend. 
(a) CWDday,ANN

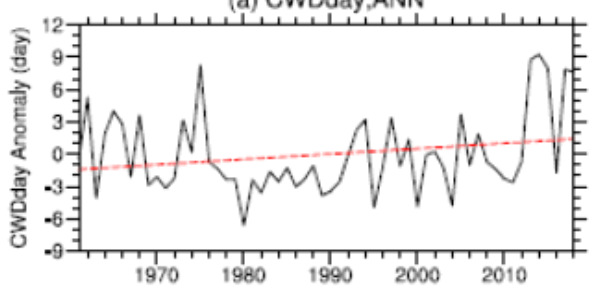

(c) CWDday,DJF

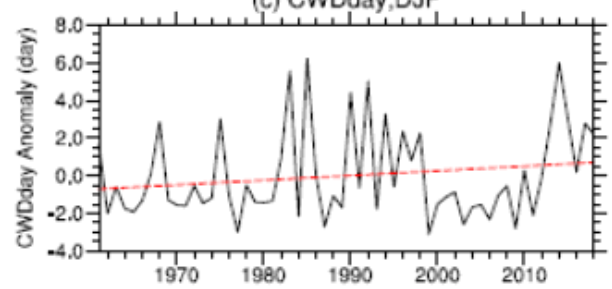

(e) CWDday,MAM

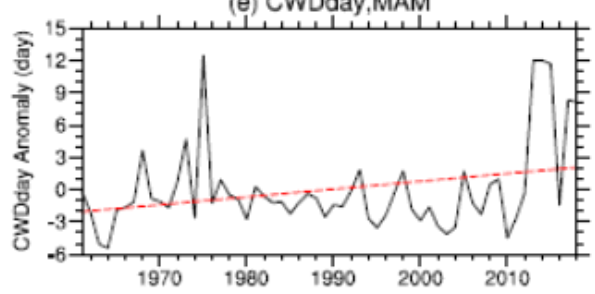

(g) CWDday,JJA

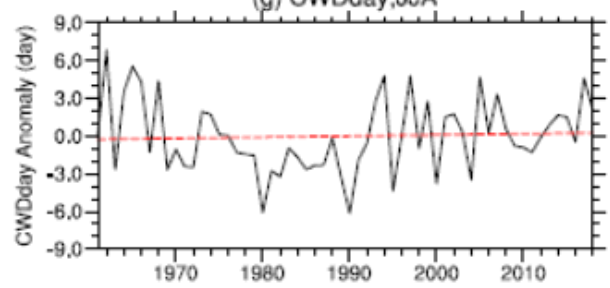

i) CWDday,SON

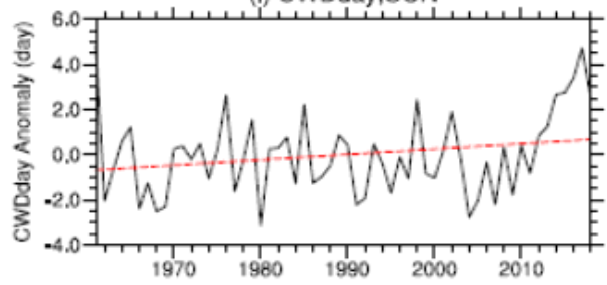

(b) CDDday,ANN

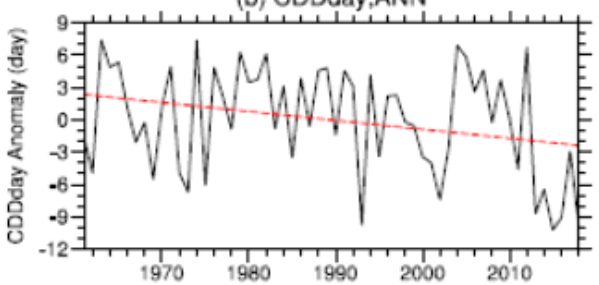

(d) CDDday,DJF

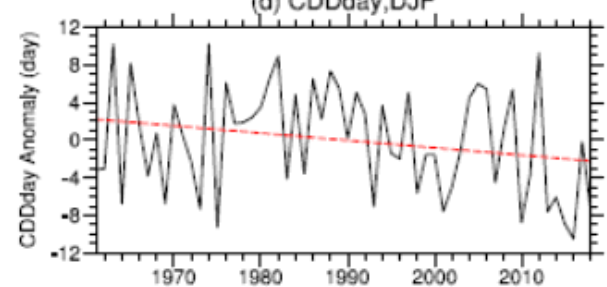

(f) CDDday,MAM

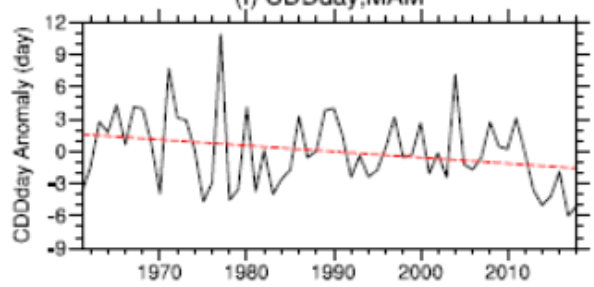

(h) CDDday,JJA

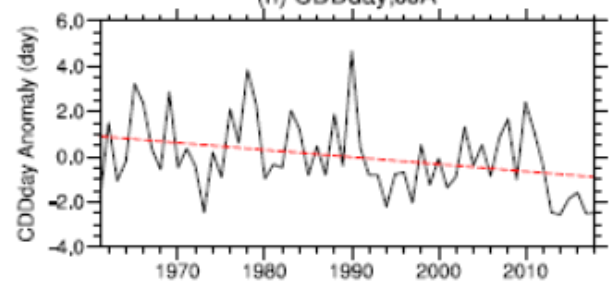

(j) CDDday,SON

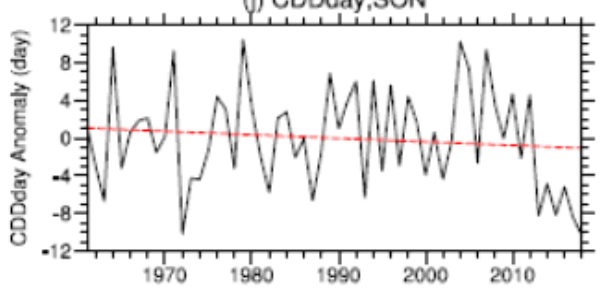

\section{Figure 4}

Variation of the regional average annual and seasonal CWDday (a,c,e,g,i) and CDDday $(b, d, f, h, j)$ anomalies in GBA from 1961 to 2018. The red dashed lines indicate the trend. 

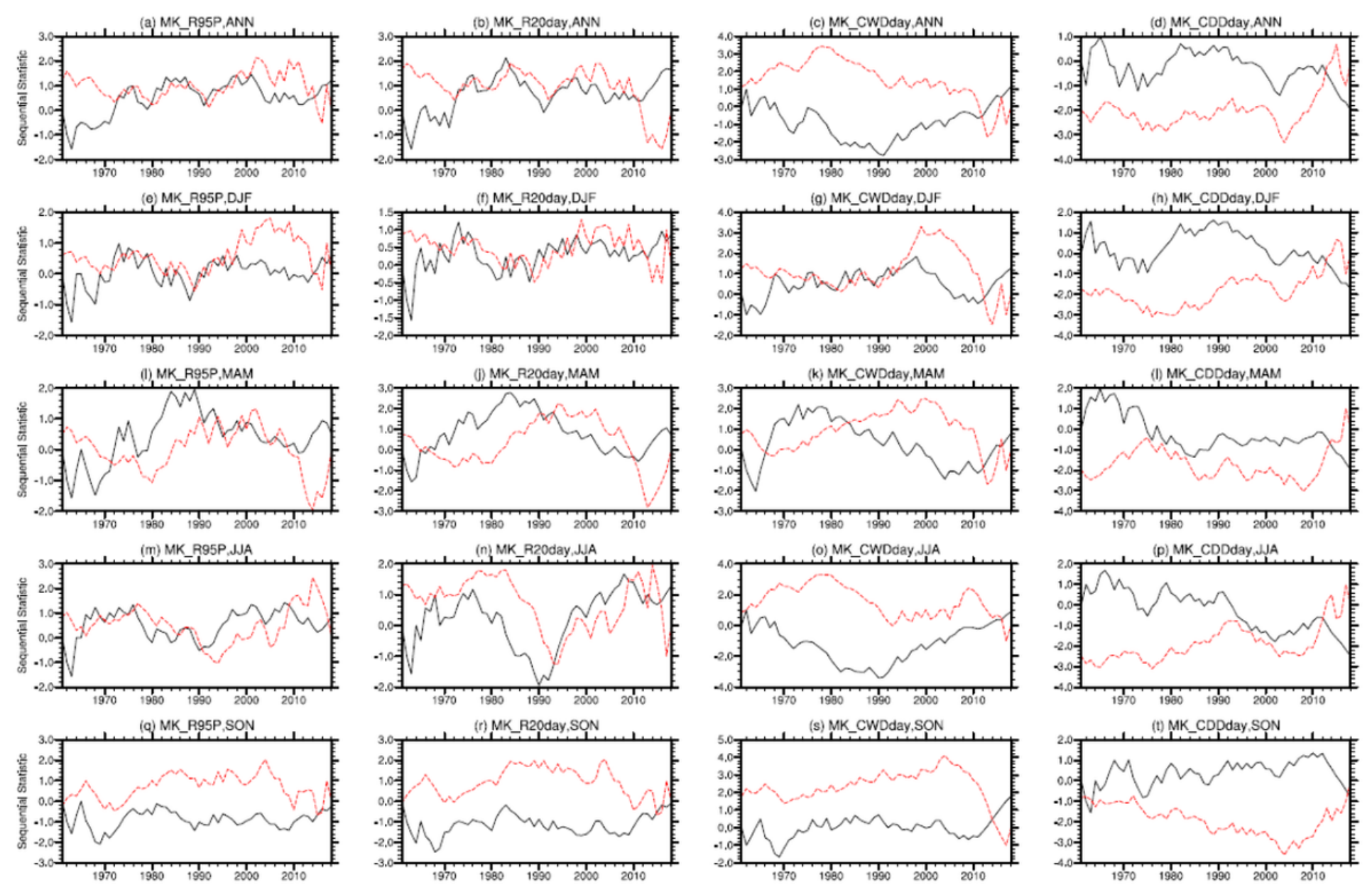

Figure 5

Abrupt changes of the regional average annual and seasonal R95P (a,e,i,m,q), R20day (b,f,j,n,r), CWDday (c,g,k,o,s) and CDDday $(d, h, l, p, t)$ in GBA as derived from the sequential version of the Mann Kendall test. The black solid and red dashed lines are the forward sequential statistics (UF) and the backward sequential statistics (UB), respectively. 

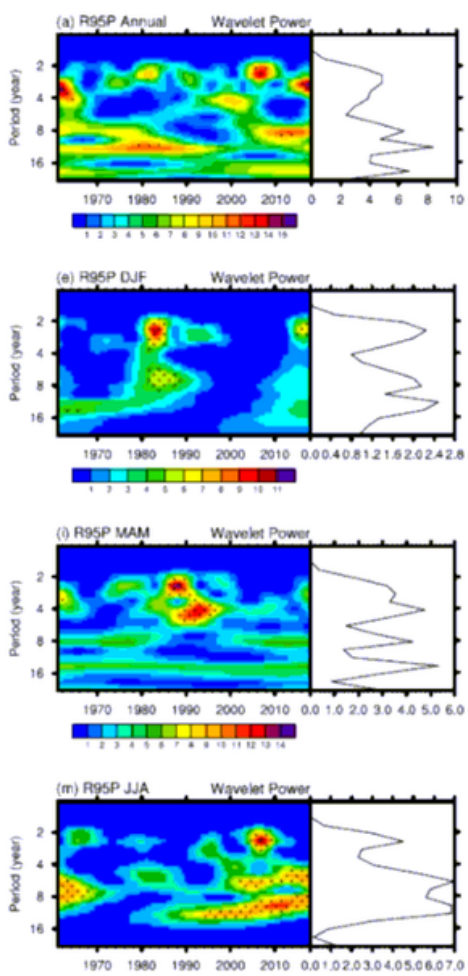

\begin{tabular}{rrrr}
$1970 \quad 1980$ & $1990 \quad 2000 \quad 2010$ \\
\hline
\end{tabular}
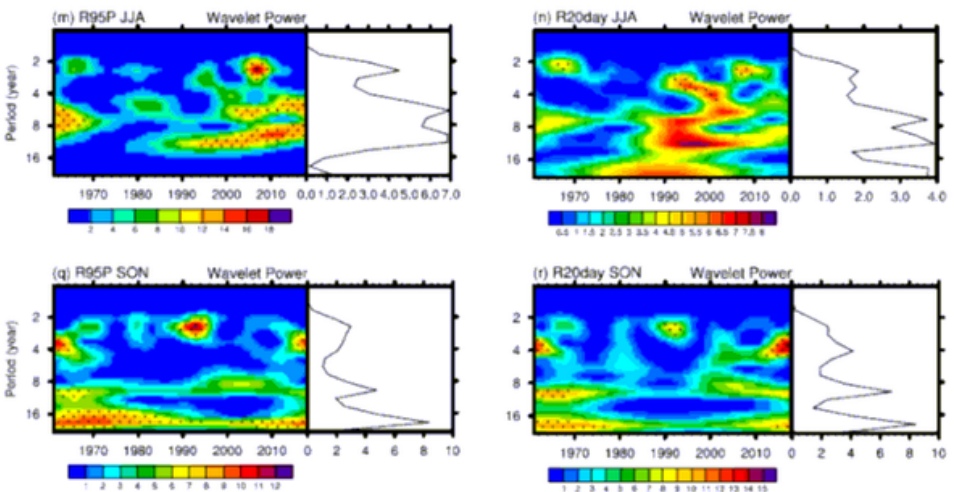
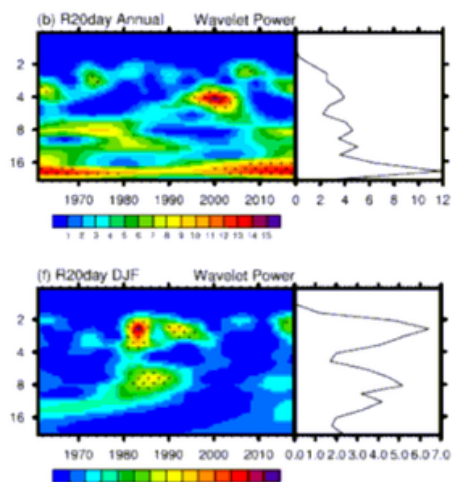

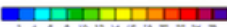
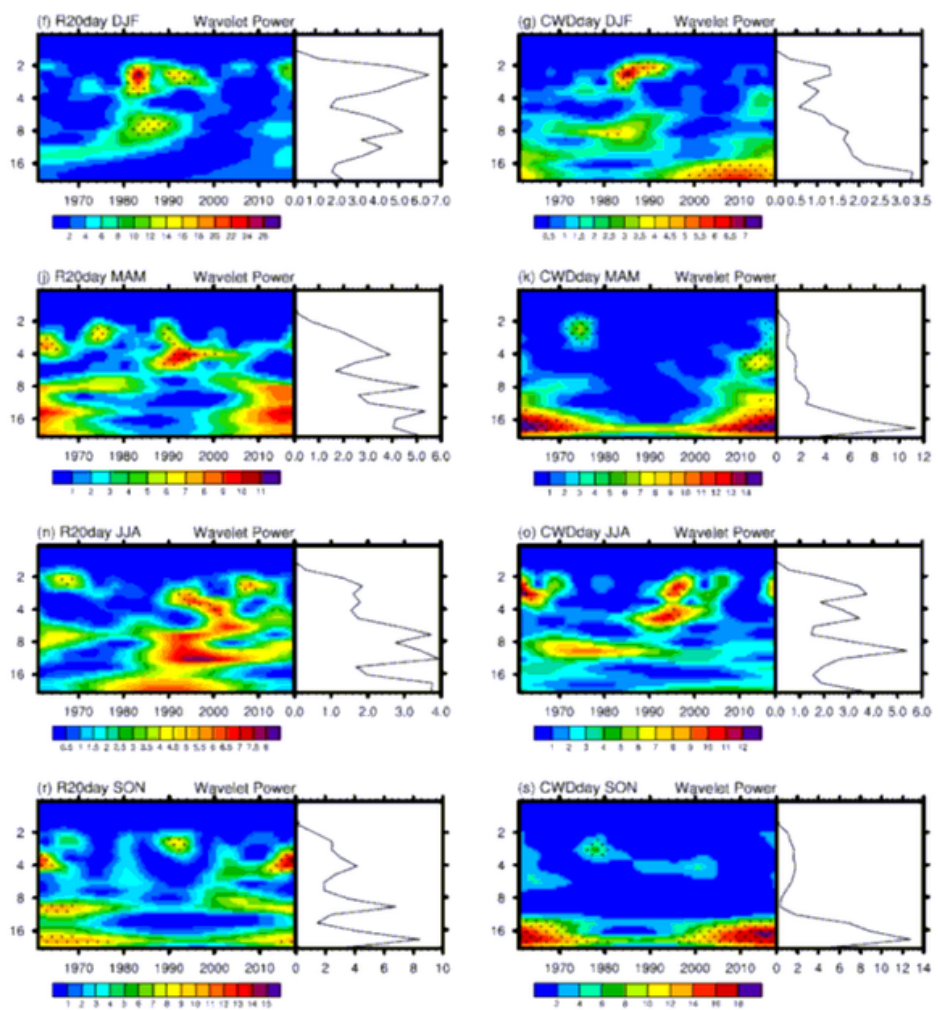

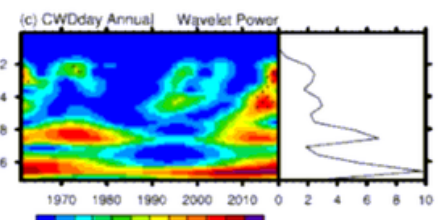

प्रा एव

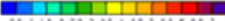
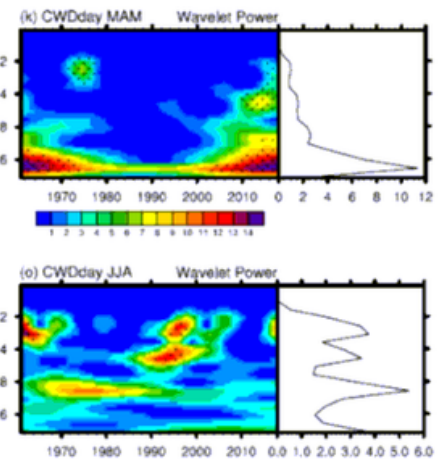

[1

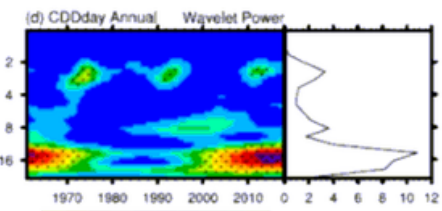

I

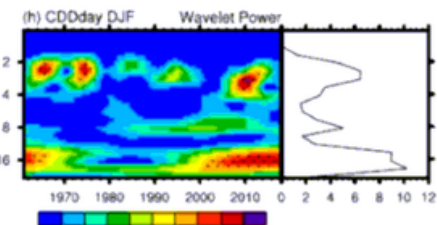

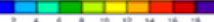
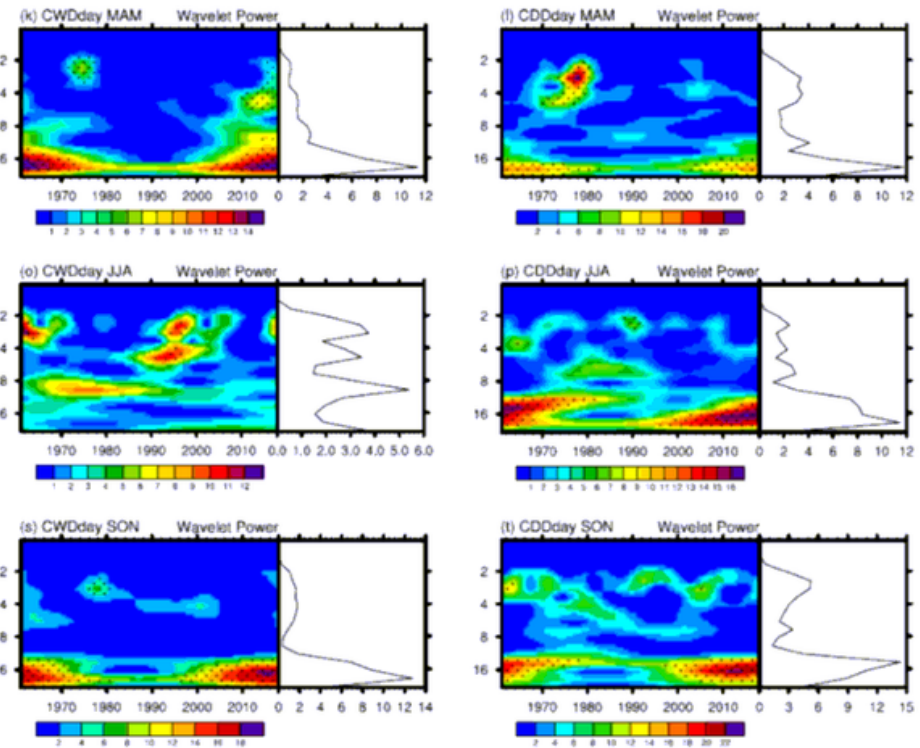

Figure 6

The Morlet wavelet analysis of the regional average annual and seasonal R95P (a,e,i,m,q), R20day (b,f,j,n,r), CWDday (c,g,k,o,s) and CDDday $(d, h, l, p, t)$ in GBA. The black dots denote the wavelet powers which are significant at the confidence level of $a=0.05$. 

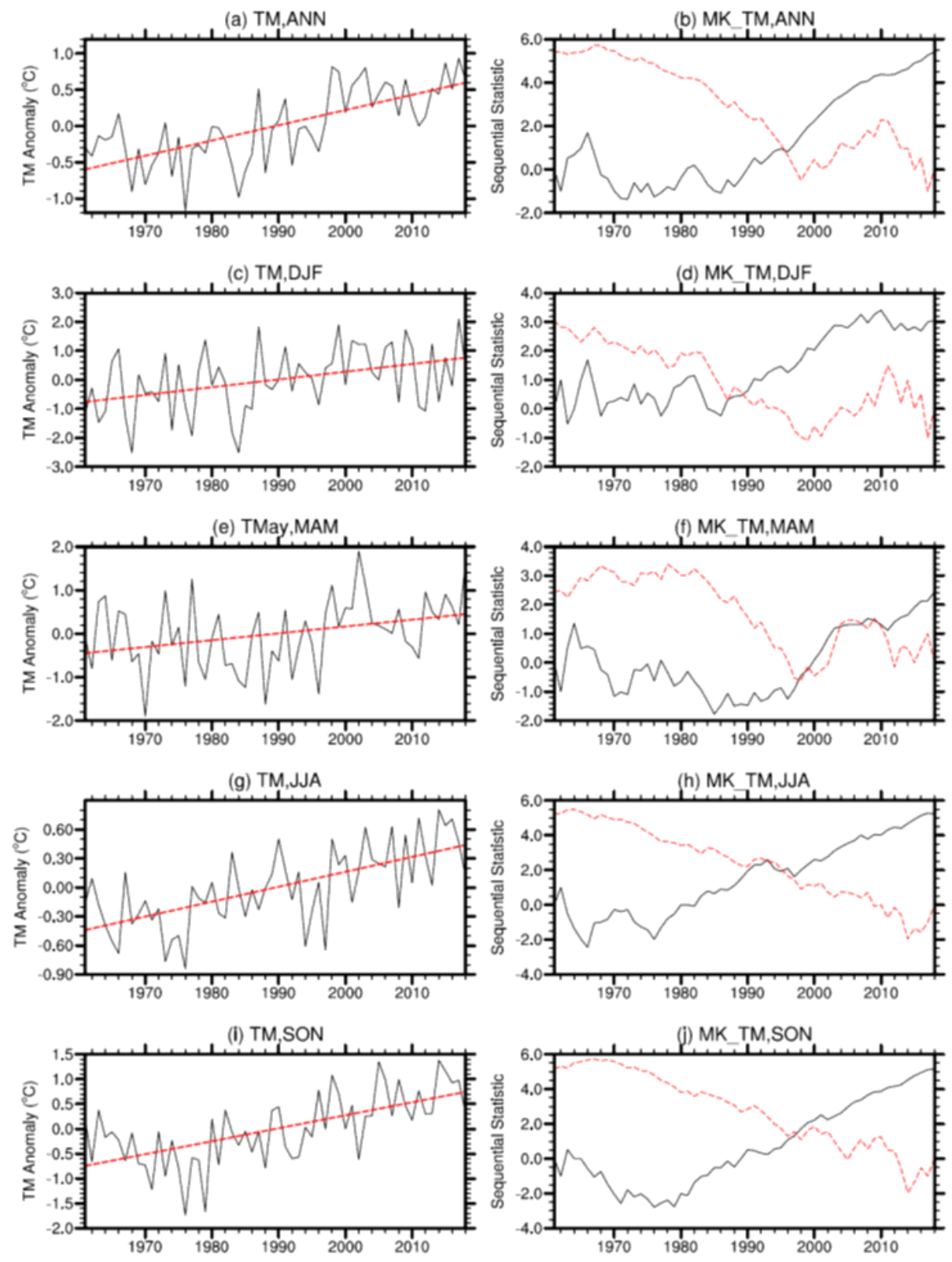

\section{Figure 7}

Inter-annual variations (left panel) and the abrupt changes (right panel) of the regional average TM in GBA as derived from the sequential version of the Mann Kendall test. (a, b) annual, (c, d) DJF, (e, f) MAM, (g,h) JJA, (i, j) SON. In left panel, the black solid and red dashed lines indicate inter-annual variation and the trend, respectively. In right panel, the black solid and red lines are the forward sequential statistics (UF) and the backward sequential statistics (UB), respectively. 
(a) PRE,ANN
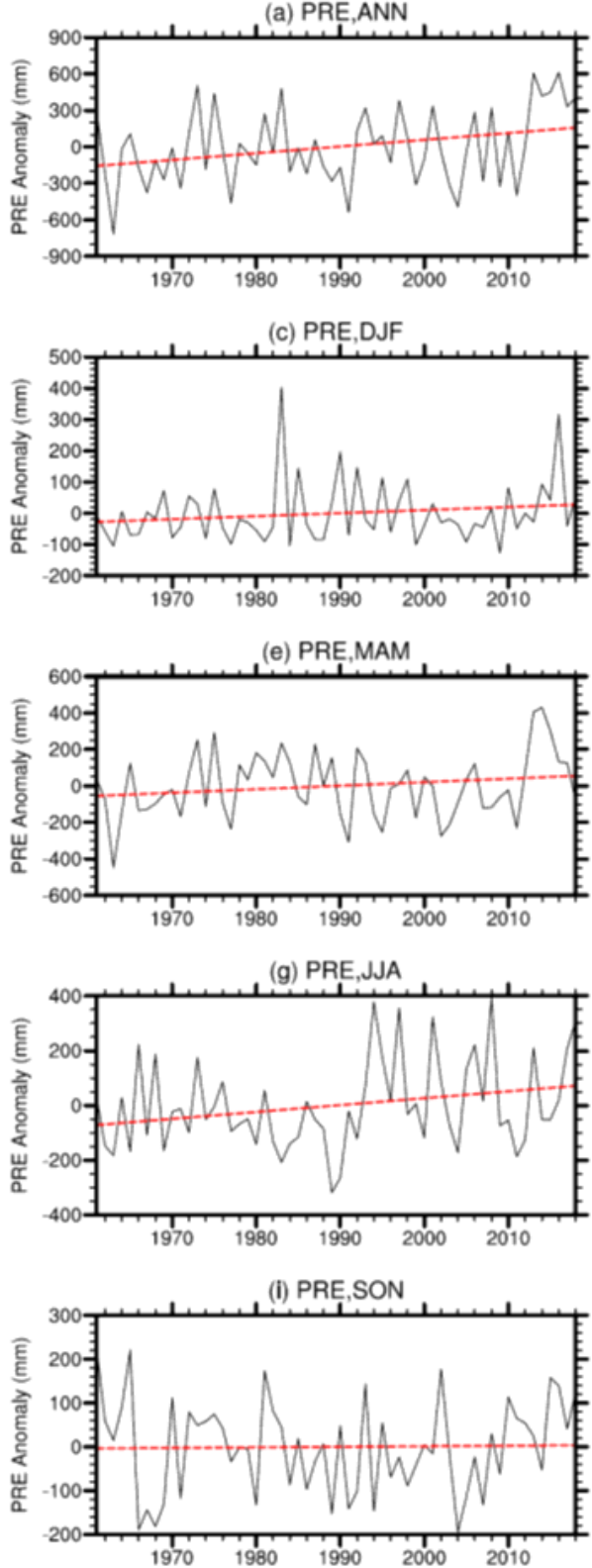

\section{Figure 8}

Same as Fig. 7 but for the regional average PRE in GBA. (b) MK_PRE,ANN
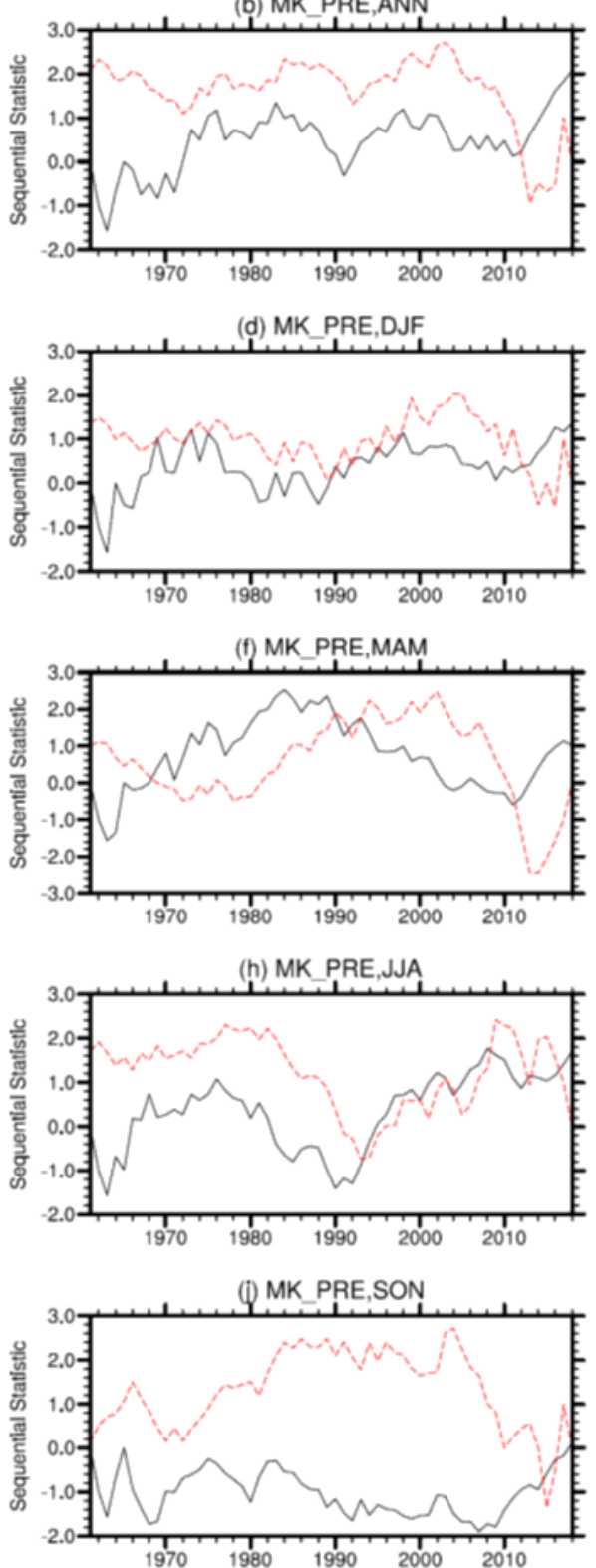

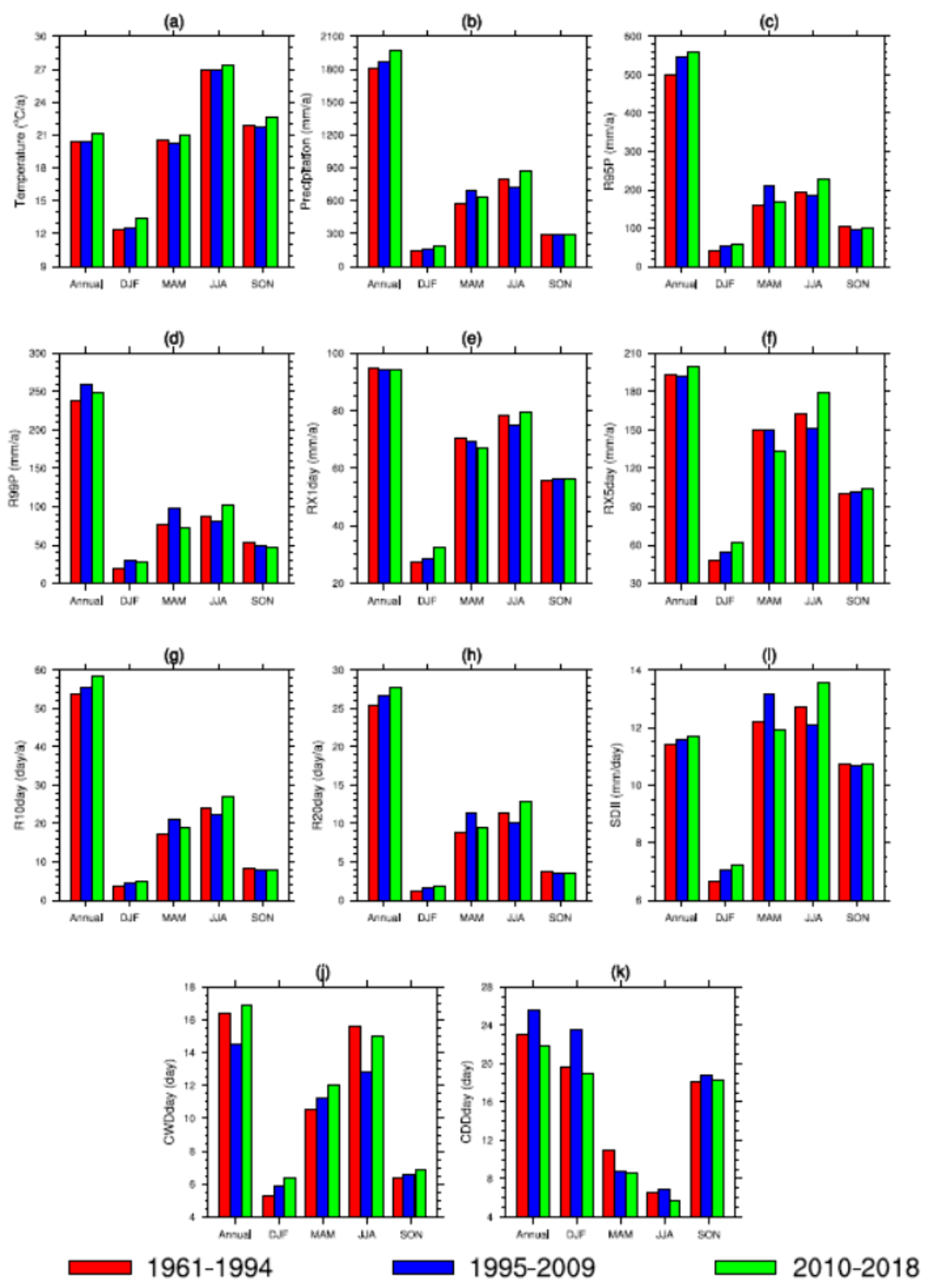

Figure 9

Changes of climate and extreme precipitations in GBA in different stages. (a) TM, (b) PRE, (c) R95P, (d) R99P, (e) RX1day, (f) RX5day, (g) R10day, (h) R20day, (i) SDII, (j) CWDday, (k) CDDday 